\title{
A CONSOLIDAÇÃO DO EMPREGO DE MODELOS EM FÍSICA A PARTIR DOS SEGUINTES TEMAS: MODELOS MECÂNICOS, UNIDADE DA NATUREZA E ESTRUTURA DO NÚCLEO ATÔMICO
}

\author{
Antonio Augusto Passos Videira ${ }^{1,2}$
}

\begin{abstract}
RESUMO
O objetivo deste ensaio consiste em argumentar, de maneira não conclusiva, em favor da tese que responsabiliza a física nuclear pela popularização, entre os físicos, do termo 'modelo'. Apesar de este termo já ser usado desde, pelo menos, o início do século XX, foi com as investigações sobre a estrutura do núcleo atômico que ele se disseminou. Finalmente, este texto questiona se a popularização deste conceito não poderia ser também explicada pela sua capacidade de permitir a uma ciência tão especializada, donde tão fragmentada, como a física a existência de canais de comunicação internos.
\end{abstract}

PALAVRAS-CHAVE: Modelo. Física Nuclear. Realidade.

\begin{abstract}
The objective of this essay is to argue, inconclusively, in favor of the thesis that blames nuclear physics for the popularization among physicists of the term "model". Although this term has been used since at least the early twentieth century, it was through research into the structure of the atomic nucleus that it spread. Finally, this text questions whether the popularization of this concept could not be explained also by its ability to allow such a specialized science, from where so fragmented, as physics the existence of internal communication channels.
\end{abstract}

KEYWORDS: Model. Nuclear Physics. Reality.

Desde o início do século passado, e sem que aparentemente este uso esteja perto do seu fim ou mesmo de um abrandamento, é cada vez mais comum os físicos recorrerem a modelos. O uso deste termo é tão difundido que ele passou a ser sinônimo de teoria. É claro que não são os físicos, teóricos e experimentais, os únicos a formularem modelos. Não há área do conhecimento que não o empregue. A presença massiva do termo 'modelo' fez com que ele se popularizasse, ainda que a custa de certa perda de rigor conceitual. Apesar de ser

\footnotetext{
1(1) Bacharel em Filosofia, Doutor em Filosofia. Universidade do Estado do Rio de Janeiro, Pesquisa apoiada pela CAPES (modalidade PRINT), FAPERJ Programa Prociência) e CNPq (Bolsa de Produtividade), email: guto@cbpf.br. Ensaio recebido em 11/10/2019 e aceito em 16/11/2019.

(2) O autor agradece a hospitalidade da Faculdade de Filosofia e Ciências Sociais da Universidade Católica Portuguesa (polo Braga), local em que este texto foi escrito.
}

Perspectivas - Revista do Programa de Pós-Graduação em Filosofia da UFT - v. 2 n. 2 (2017) 
relevante discutir as suas razões, bem como as próprias perdas, não é isto que será tratado neste texto.

Se, antes - até meados do século passado, aproximadamente -, os modelos eram percebidos como provisórios, sendo necessários apenas para uma exploração inicial de um conjunto de fenômenos desconhecidos, realizados com o propósito de se conseguir dados quantitativos e informações qualitativas sobre os fenômenos em consideração, a partir de certo momento, o qual coincide grosso modo com o começo da preocupação em se entender os fenômenos eletromagnéticos, o que foi reforçado com as pesquisas acerca da estrutura da matéria, os modelos passaram a ser percebidos como inevitáveis ou, até mesmo, como um mal necessário. Com a criação da mecânica quântica, o emprego de modelos conheceu uma disseminação crescente.

O momento decisivo para a consolidação da presença de modelos na física coincide com o advento da física nuclear, evento que se situa entre o final da década de 1920 e o início da década seguinte. A generalização do uso de modelos implicou diferentes consequências, entre as quais a perda de unidade, o que foi lamentado pelos físicos mais afeitos à chamada física clássica (aqui entendida como todo o restante da física, excetuando-se a mecânica quântica e suas aplicações), e a diminuição da relevância da verdade como correspondência como critério para a escolha entre modelos e teorias rivais.

Mesmo o uso de modelos contraditórios entre si passou a ser aceitável, uma vez que os físicos se tornaram mais flexíveis em suas atitudes e crenças epistemológicas e metafísicas. Se os resultados científicos correspondiam às previsões formuladas, incoerências e contradições eram deixadas de lado, pelo menos até um momento posterior, quando aquelas deveriam ser diretamente atacadas e, se possível, resolvidas.

O objetivo deste ensaio consiste em justificar, sem que isto signifique que eu queira provar, a coerência das afirmações acima a partir da investigação de como os físicos - em particular, aqueles que se preocuparam com a estrutura nuclear da matéria, entre os quais Ernst Rutherford, Niels Bohr, Hans A. Bethe, Werner Heisenberg, enfrentaram a tarefa de mostrar a estrutura e a organização do núcleo atômico - reconheceram a necessidade de recorrerem a modelos em sua prática científica.

Ao longo deste breve ensaio, eu argumentarei em favor da tese de que os modelos se tornaram elementos obrigatórios na prática científica a partir do momento em que os cientistas - em particular, os físicos - conscientizaram-se de que a realidade (ou real ou natureza ou ainda mundo externo) era mais diferente e complexa do que eles então 
consideravam. Ao perceberem, através das investigações ligadas aos fenômenos térmicos, elétricos e magnéticos, que a realidade parecia comportar propriedades, ou características, inusitadas, os cientistas naturais começaram a se movimentar na seguinte direção: ao invés de procurarem partir do pressuposto que a realidade é regular, harmoniosa, uniforme e estável, já que ela possuiria com limites (fixados mesmo que fosse por Deus), limites que a tornariam inteligível à razão humana, o mais adequado seria esquecer que a inteligibilidade da natureza repousaria na sua extensão finita. Em outras palavras, o conhecimento de uma determinada região da realidade não decorreria do fato de que toda a natureza seria semelhante àquela. A natureza seria constituída por regiões diferentes - em sentido ontológico - entre si. Se não é mais possível ancorar o conhecimento do real, a possibilidade que restaria aos cientistas seria localizá-lo nas capacidades da razão humana em compreender "coisas", entre as quais o real. O investimento deveria ser, portanto, nas estruturas, que criamos ao usarmos a nossa inteligência como, por exemplo, modelos, teorias, leis, entre outras. Todavia, essa ancoragem deve respeitar, sempre que possível, àquilo que ocorre na realidade.

Essas estruturas são como os instrumentos empregados para tatear as profundezas de um rio percorrido e do qual não se vê, e nem se pode ver, o leito. A realidade não é diretamente - visível. Precisamos recorrer a instrumentos (materiais ou conceituais) para poder interagir com ela. Se assim for, o melhor é aperfeiçoar tais instrumentos, sem nunca perder de vista a proximidade que eles devem guardar, não mais com o real, mas, sim, com aquilo que somos capazes de produzir. Por vias imprevistas, o homem voltou a ser a medida para o estudo e o entendimento da natureza. Lembremo-nos do uso da sentença de Protágoras - 'o homem é a medida de todas as coisas' - pelos positivistas lógicos. Creio que o mesmo pensamento ou, se preferirem, a mesma atitude foi defendida por Ludwig Boltzmann, quando este acreditava ser necessário recorrer a mecanismos palpáveis, donde manipuláveis pelos seres humanos. Segundo o físico austríaco, o que, segundo ele mesmo, teria sido já afirmado por James Clerck Maxwell, a teoria física nada mais é do que uma construção mental de modelos mecânicos, cujo funcionamento decorre de um planejamento humano feito com base em analogia com mecanismos, que "seguramos em nossas mãos", os quais por serem assemelhados aos fenômenos naturais, podem nos ajudar a compreender tais fenômenos.

Ao afastar-se da realidade conhecida, aproximando-se das estrelas ou dos átomos, o cientista deve assegurar-se de que os instrumentos conceituais e materiais que usa são 
confiáveis, não são imaginados de forma arbitrária, como que correspondendo às suas próprias preferências pessoais. Como afirmado após 1902, ano de publicação do verbete, no qual estão expostas as ideias de Boltzmann sobre o emprego de modelos nas ciências naturais, um modelo é "um guia qualitativo para o nosso pensamento", nos termos do físico norte-americano Robert Leighton. Diferentemente de Boltzmann, Leighton enfatiza o caráter qualitativo dos modelos, na medida em que os modelos são essencialmente estruturas matemáticas, sem se preocupar se eles poderiam ser efetivamente construídos.

Essa caracterização dos modelos também é defendida pelo igualmente físico teórico inglês John Ziman, o qual, a partir da década de 1960 dedicou-se à filosofia da ciência e aos estudos sociais de ciência e tecnologia. Para Ziman, uma teoria científica seria uma análise das características de um modelo hipotético. Em se tratando da física, a qual pode ser entendida como uma tentativa de fazer com que o universo passe estar subordinado à matemática, Ziman afirma que os modelos podem ser percebidos como que constituindo algo semelhante a um exercício intelectual de natureza matemática. Mais uma vez, os modelos são descritos como estruturas abstratas, ainda assim eles não devem ser vistos como irreais ou fantasiosos. Para os modelos serem vistos como reais, eles deveriam estar associados, de alguma maneira, à materialidade, como enfatizado por Boltzmann no seu verbete ou como pode ser igualmente encontrado em obras de mecânica aplicada.

O físico britânico Edward Routh, autor de um célebre livro de mecânica do final do século XIX, associa o uso de modelos aos testes de grandes construções como, por exemplo, navios. Modelos seriam relevantes para a engenharia, principalmente a partir do momento em que novos materiais (aço e concreto armado) começam a se popularizar como componentes de edificações, muito maiores do que aquelas até então conhecidas e construídas. Para a não tão nova ciência da resistência dos materiais, de certo modo criada por Galileu, os modelos são fundamentais. Routh defendia que, ao compararmos o funcionamento de um modelo com aquele outro de uma máquina grande, é preciso levar em consideração todas as forças nas proporções adequadas.

No entanto, nem sempre é possível recorrer a modelos materiais, como máquinas ou maquetes, para garantir a confiabilidade dos modelos abstratos e matemáticos. Isso se torna evidente quando olhamos para a física teórica do século XX: teoria da relatividade, mecânica quântica, física nuclear e física de altas energias. Nessas áreas, nas quais é impossível construir modelos materiais dos fenômenos naturais, os modelos, justamente por serem guias, tornam-se imprescindíveis, tal como defendido por Leighton, para quem o processo 
de visualização de um fenômeno físico ainda mal compreendido em termos de objetos e ideias familiares, além de comum, ser praticamente indispensável para avançar no tratamento teórico de fenômenos físicos. Ainda segundo Leighton, o desenvolvimento da física tem sido fundamentalmente um processo de representar o mundo físico através de modelos, que incorporam ideias qualitativas fundamentais, elaboradas a partir da recolha de aspectos qualitativos simples do comportamento. Aquilo que era uma novidade enorme na época de Maxwell e Boltzmann, três quartos de século depois tinha se tornado algo óbvio e natural. É como se a busca pela formulação de teorias unificadas para a física representasse a escolha por um comportamento inusitado e estranho. Essa mudança de atitude corresponde à outra, relativa à natureza da realidade estudada pelo físico.

Tal mudança foi bem caracterizada pela física teórica francesa, Marie Antoine Tonnelat, a qual pode ser vista como preservando o respeito pela distinção hierárquica entre teoria e modelo, em favor da primeira. Para Tonnelat, a possibilidade de formular teorias físicas decorre de um princípio unitário (unitaire). Ao propor uma interpretação comum de certos fenômenos e ao descrever experiências diferentes com a ajuda de um mesmo formalismo, o físico recorreria a um princípio que confere unidade, seja à sua interpretação, seja à sua descrição. Inspirada em Einstein, Tonnelat parecia acreditar em 1965 ser necessário manter uma distinção forte entre teoria e modelo, distinção já era desacreditada pelos físicos nucleares e de altas energias. Subjacente à teoria, sempre de acordo com a física francesa, estaria presente uma concepção forte de real, devida à existência de uma realidade objetiva.

Mas, como provar a unidade da realidade? Tonnelat reconhece que tal prova, em termos lógicos, epistemológicos ou metafísicos, é impossível. Ainda assim, a existência de uma realidade, que poderia ser unificada por meio de uma teoria unitária, é o sustentáculo de uma física que se pretende explicativa e racional. Na medida em que esta pretensão não se realizou até hoje, ela é se origina em uma exigência moral, correspondendo a uma decisão tomada pelos cientistas a partir de suas concepções filosóficas. O uso de modelos enfraqueceria, portanto, a posição realista, ao menos aquela supostamente defendida pela tradição inaugurada por Galileu e Newton e consagrada por Einstein.

Para os defensores do uso de modelos, é necessário provar que eles são guias confiáveis no estudo da realidade, mesmo que de uma pequena parte desta última. Em outras palavras, os modelos devem ser interpretados realisticamente para que possam ser confiáveis. Como fazer isso - torná-los reais - quando eles servem para investigações de 
fenômenos que acontecem em dimensões muito 'distantes' daquelas com as quais estamos familiarizados? Já os defensores do uso de teorias precisam provar que estas são factíveis e não correspondem a sonhos megalomaníacos daqueles que acham possível conhecer a totalidade. Afinal, como seria possível conhecer a totalidade, dado que a mente humana é finita ou limitada?

Continuemos com madame Tonnelat. Segundo ela, Einstein, talvez mais do que qualquer outro físico contemporâneo, exigia que a inteligibilidade e a eficácia da ciência estivessem baseadas na posição realista expressa acima. Contudo, como exprimir e, principalmente, justificar essa exigência? Inúmeros filósofos e cientistas formularam argumentos engenhosos, mas que não resistiram seja a outros argumentos, seja à confrontação com a realidade empírica. Os cientistas estariam como que condenados a oscilar continuamente entre dois polos. De um lado, o polo constituído pelas medidas físicas; de outro, aquele representado pelas contribuições dadas pelo espírito humano, o qual se descobre, durante o trabalho de síntese, consciente da necessidade e também da fragilidade das categorias que ele introduz.

As ideias de Tonnelat, ecoando aquelas do físico teuto-suíço-americano, expressam a tese de que a reunião das medidas com as categorias somente poderia ocorrer numa esfera, situada em um plano diferente dos dois polos, ensejando a crença na existência de uma divisão insuperável entre teoria e prática.

Em que pese os problemas decorrentes dessa divisão, creio eu que ela não é intrinsecamente negativa, uma vez que o 'espírito humano' se torna consciente das suas habilidades, justamente ao tentar sintetizar aquilo que se recusa a ser encaixado em sínteses, quaisquer que sejam elas. Poder-se-ia imaginar que o pressuposto para tal atividade de síntese, praticada pelo espírito humano, estaria fundada na, ou decorre da, sua liberdade em imaginar, ou produzir, conceitos e categorias? Em outras palavras, a nossa capacidade de movimentação entre os dois polos (medidas e conceitos), mesmo que para sempre, recebe uma interpretação positiva, caso aponte para a liberdade de escolher o polo preferido, permitindo a escolha dos conceitos ou ainda das medidas a serem realizadas. Os cientistas são livres, ao menos enquanto seres cognitivos, porque formulam sínteses que não funcionam, ao menos em sentido rigoroso e definitivo, uma vez que jamais correspondem à totalidade.

Segundo o físico e historiador da física de origem holandesa Abraham Pais, o desenvolvimento da física nuclear teve três fases distintas desde o final do século XIX 
(radioatividade e modelos da estrutura do elétron) até o momento em que ocorreu a descoberta da fissão nuclear, já no final da década de 1930. Dessas três fases, as duas primeiras foram marcadamente empíricas, na medida em que os principais resultados ocorreram na área experimental, devido à inexistência de um quadro teórico necessário para a formulação de leis capazes de descrever os fenômenos, que ocorriam na escala do núcleo atômico.

Nas primeiras três fases do desenvolvimento da física nuclear, é possível encontrar algumas abordagens típicas de uma física de tipo fenomenológica, isto é, a atividade se concentra na formulação de leis (relativamente) gerais que descrevem os comportamentos se possível - observados em laboratório. Em termos gerais, creio que a importância concedida a um esquema como este proposto por Pais decorre do fato de que, para os historiadores adeptos da chamada história internalista, a 'boa' ciência deve o seu começo a novos descobrimentos experimentais e à criação de novos instrumentos. Deste modo, o surgimento de uma nova área de investigação como a física nuclear é uma decorrência obrigatória da própria natureza, uma vez que ela nos mostra novas facetas através de fenômenos até então desconhecidos.

Esta posição pode ser reforçada a partir da menção a outros dois historiadores, igualmente internalistas: Laurie Brown e Helmut Rechenberg, os quais acreditavam que ao longo dos anos, após a aceitação do átomo nuclear de Bohr-Rutherford, ocorreu um considerável progresso na determinação de propriedades dos núcleos atômicos, principalmente devido à mensuração precisa de pesos atômicos e devido a experimentos sobre transformações nucleares por meio de partículas alfa e, posteriormente, devido a prótons rápidos. Ainda de acordo com Brown e Rechenberg, a oficialização da perspectiva fenomenológica em física nuclear teria se dado com Heisenberg no ano de 1932, quando ele propôs o seu modelo nêutron-próton (n-p), que se tornou num concorrente bem sucedido do até então modelo dominante o elétron-próton (e-p).

Em que pese a importância de Heisenberg, é Ernst Rutherford o físico mais importante na área da física nuclear no período compreendido por este trabalho: a primeira metade do século XX, não apenas pelos resultados que obteve, mas também pelo fato de que alguns de seus colaboradores, como James Chadwick, Francis Williams Aston e Charles Drummond Ellis, se destacaram nas investigações relativas ao núcleo atômico. Deve igualmente ser mencionado que Niels Bohr propôs suas ideais sobre como quantizar os movimentos dos elétrons após ter estagiado no laboratório de Rutherford, quando este ainda trabalhava em 
Manchester, o que reforça a relevância que Rutherford desfrutou nas primeiras três décadas do século passado na área dos estudos relativos à constituição dos átomos.

Mas os resultados de Rutherford ainda não eram devido ao uso da mecânica quântica. A aplicação desta nova teoria física a fenômenos nucleares ocorreu no final da década de 1920. Em 1928, George Gamow conseguiu o primeiro resultado considerado correto a partir da aplicação da nova mecânica quântica: a radioatividade da partícula alfa foi explicada como um tunelamento ou penetração de uma barreira de tipo quântica.

Finalmente, o terceiro problema era o decaimento beta nuclear, para cuja compreensão Enrico Fermi, em 1934, deu uma contribuição decisiva, ao incorporar o neutrino ao seu modelo, permitindo que se mantivesse a conservação do princípio de energia. O modelo e-p (elétron-próton) sofria de várias dificuldades, entre os quais o paradoxo quântico da estatística do spin e da dificuldade de manter elétrons leves sem que eles escapassem do pequeno volume nuclear, ou seja, que permanecessem confinados no núcleo atômico. $\mathrm{O}$ modelo de Fermi mostrou também que os elétrons não estavam localizados no núcleo atômico, mas eram criados no momento do decaimento.

A perspectiva historiográfica classificada como internalista recebeu, ao longo de todo o século XX, inúmeras críticas, entre as quais merece destaque a sua idealização da prática científica. Preocupada com a garantia da autonomia para os cientistas, tal perspectiva historiográfica teria descaracterizado a prática da ciência. Essa descaracterização tornou-se ainda mais criticável a partir do momento em que o mundo conheceu as bombas atômicas e o seu enorme poderia de destruição.

De acordo com o historiador da ciência Jeff Hughes, a partir da década de 1980, ocorreu um esforço de compreender o desenvolvimento da física nuclear em um cenário mais amplo. Ao invés de privilegiar os desenvolvimentos teóricos, a nova perspectiva historiográfica percebe a radioatividade e a física nuclear como estando na interseção da academia com a indústria e com o estado. Em vez de considerá-los evidentemente significativos, tal perspectiva, que incorpora elementos teóricos, políticos e instrumentais, considera os cientistas, engenheiros e técnicos como justificando ativamente seu próprio trabalho uns com os outros e seus esforços coletivos com outros cientistas, bem como com a comunidade em geral. A era nuclear passa a ser compreendida como uma realização contingente, e não como um resultado inevitável, da atividade científica. Segundo Hughes, um dos resultados mais interessantes dessa perspectiva historiográfica relativamente recente 
é a possibilidade de perceber que a evolução da física nuclear não seguiu nenhum caminho "lógico" ou coerente à partida.

Considerando que o início da física nuclear estaria localizado nas pesquisas realizadas por Rutherford, os Curie e Becquerel, na passagem do final do século XIX para o seguinte, Hughes sustenta que os praticantes de radioatividade vieram de origens diferentes. Os modos pelos quais eles se situavam na disciplina, então nascente, e como eles desenvolveram a radioatividade pratica e intelectualmente, dependeram, e muito, da sua formação intelectual anterior, além de igualmente respeitarem o seu treinamento prático. Assim, Rutherford, treinado na tradição da física iônica de Cambridge, promoveu uma abordagem teoricamente reducionista do assunto. Já os Curie e seus herdeiros, herdeiros de uma tradição fortemente positivista, trabalharam em linhas predominantemente químicas, evitando a abstração teórica. Em vários lugares, a colaboração entre químicos e físicos foi importante - como Rutherford e Soddy, em Montreal, ou Otto Hahn e Lise Meitner no Instituto Kaiser Wilhelm de Química, em Berlim.

A impossibilidade de conferir um desenvolvimento coerente à física nuclear tem outra consequência, ainda não suficientemente discutida na literatura. Refiro-me à situação de que mesmo as diversas especialidades, as quais, tal como a física nuclear, constituem a física, não possuem unidade, sendo possível caracterizar as suas práticas como próximas a uma colcha de retalhos. Entre as décadas de 1890 e 1930, ou seja, durante 40 anos aproximadamente, não existiu consenso com relação ao modelo, dentre as muitas possibilidades então disponíveis, deveria ser considerado como o 'melhor'. A formulação e divulgação de modelos do núcleo atômico continuaram a ser a regra nesse período. Somente com a formulação de modelos matemáticos do núcleo atômico, esforço encetado primeiramente por Bohr e Arnold Sommerfeld, é que passou a se constituir certa unanimidade a respeito de como seria possível descrever e explicar os fenômenos nucleares conhecidos através da espectroscopia.

Na segunda metade da década de 1930, Bohr e colaboradores, recorrendo a ideias de Gamow, formularam o modelo da gota do núcleo atômico, chegando, assim, à noção de núcleo como algo composto e nada trivial. Este modelo, por ter sido capaz de organizar de forma coerente a enorme massa de dados empíricos que se passou a conhecer desde então, ganhou notoriedade e dominou a teoria em física nuclear ao longo das décadas de 1940 e 1950. O seu concorrente mais próximo foi o modelo de camadas, que recebeu uma 
formulação considerada como cientificamente aceitável através dos trabalhos de Maria Goeppert-Mayer e Hans Jensen, entre outros.

Ao longo dos anos de 1920 e 1930, trabalhos foram publicados com o objetivo de organizar a então jovem área da física nuclear. Grande parte desses trabalhos já era considerada como ultrapassada no próprio momento em que vinham à luz, posto que novos dados e resultados experimentais colocavam em xeque ou mesmo refutavam afirmações feitas neles. Nos anos de 1936 e 1937, conseguiu-se finalmente dispor de trabalhos que, devido à sua capacidade de síntese, diminuíram o grau de dispersão e 'espalhamento' que caracterizava a física nuclear. Em três artigos publicados na Review of Modern Physics na segunda metade dos anos 1930, Hans A. Bethe, contando com a colaboração de Robert Bacher e Stanley Livingston, conseguiu reunir praticamente todo o conhecimento, então disponível, a respeito do núcleo atômico. Os artigos de Bethe, que passaram a ser conhecidos a Bíblia de Bethe, tinham três partes, as quais discorriam sobre as propriedades dos núcleos, forças nucleares, radiações alfa, beta e gama, nêutrons e deutérios, a teoria estatística de núcleos pesados, momentos nucleares, processos nucleares como problemas de muitos corpos, espalhamento e métodos e dados experimentais. A Bíblia Bethe permaneceu como o trabalho de referência padrão em física nuclear até os anos 1950.

A Bíblia de Bethe alcançou fama não por ter sido capaz de formular uma visão teórica suficientemente poderosa e fecunda capaz de unificar numa descrição matemáticoconceitual toda a enorme quantidade de dados empíricos colecionados sobre o núcleo coletados até o momento da redação. Respeitando o caráter 'retalhado' (não unificado) das pesquisas nucleares, Bethe se propôs a criar uma classificação para diminuir o grau de confusão, que grassava entre os especialistas nucleares. Antes de ser um artigo, a Bíblia de Bethe é, na verdade um relatório minucioso, construído a partir de uma fina e competente seleção da literatura realmente relevante. Em outras palavras, o sucesso de Bethe pode ser entendido pelo fato de que, naquela altura, os modelos, não apenas já eram de uso corrente na física nuclear, mas já eram vistos como 'instrumentos' úteis e desprovidos de dificuldades ou fraquezas epistemológicas, as quais poderiam diminuir a sua relevância.

Não é difícil mencionar nomes de físicos importantes que permaneceram incomodados com esta situação. Werner Heisenberg, por exemplo, jamais se conformou com a natureza retalhada da descrição que a física dava para a natureza, como se pode perceber nos comentários críticos que dirigia ao uso de teorias e modelos fenomenológicos. No entanto, mesmo ele foi obrigado a reconhecer e a se comportar em certas situações como se os 
modelos fossem, não "males necessários”, mas, sim, como 'instrumentos' naturalmente adequados para a melhor compreensão possível dos fenômenos nucleares.

Sem que possa assegurar que a conclusão, com qual pretendo finalizar este texto, é verdadeira, mas ao menos, como espero, plausível, eu acredito que a estabilidade que a física nuclear passou a desfrutar em finais da década de 1930 deve-se não a uma contribuição dada pela filosofia através do empréstimo de conceitos ou princípios generalizantes, mas ao respeito à situação que já era então evidente e incontornável. A física, no seu afã de entender a estrutura da natureza íntima da matéria, tinha se tornado dependente dos laboratórios bem equipados.

Se as observações históricas e os comentários epistemológicos, feitos ao longo deste ensaio, são coerentes (i.e. plausíveis) e sustentáveis, parece-me que o emprego de modelos se consolidou justamente pela sua capacidade de encontrar uma relação equilibrada, ou melhor, fecunda entre teorização e experimentação, ambas consideradas a partir da perspectiva de uma prática coletiva, e não mais como atividades realizadas de modo individual. A transformação sofrida pela prática entre os físicos científica acabou por levar a que o termo modelo se transformasse no elemento de ligação entre as diferentes subcomunidades, ou grupos, que compõem a física, ainda que o preço a ser pago tenha sido o da perda da possibilidade de compreender a realidade (ou natureza) como uma entidade unificada, o que parece não ter sido lamentado por muitos membros desta comunidade. 